\title{
Head Nurses' Perception of Their Managerial Skills and Its Relation To Their Patient Advocacy
}

\author{
Eman Farouk Abd-El Menem ${ }^{1}$, Nermin Mohamed Eid², Mahdia Morsi El- \\ Shahat $^{3}$ \\ ${ }^{1}$ Nursing Administration, Faculty of nursing, Menoufia University. ${ }^{2}$ Professor., Nursing \\ Administration, Faculty of Nursing, Menoufia University. ${ }^{3}$ Nursing Administration, Faculty of \\ Nursing, Benha University.
}

\begin{abstract}
Background: Head nurses' managerial skills affect the quality of health care which is reflected on patient's advocacy. The purpose of the study was to assess head nurses' perception to their managerial skills and its relation to their patient advocacy. Design: A descriptive correlational design was utilized. Setting: The study was conducted at Medical and Surgical departments at Benha University Hospital. The study sample is composed of 68 head nurses and their assistants. Instruments: Two instruments were used for data collection (Managerial Skills Questionnaire and patient Advocacy Questionnaire). Results: More than half(51.5\%, 55.9\%) of study subjects had high perception of conceptual and interpersonal skills as respectively while half of them had moderate perception of leadership and more than two thirds $(69.1 \%)$ of them had moderate perception of technical skills. More than three quarters (77.9\%) of study subjects had positive perception of patient rights while more than two thirds $(72.1 \%)$ of them had positive perception to their responsibilities for patient's advocacy. Conclusion: There was a highly statistical significant positive correlation between head nurses and their assistants' perception to their total managerial skills and their total patient advocacy. Recommendations: Hospital management has to develop clear policies regarding patient rights and advocacy. In-service training is needed for head nurses each year to gain technical and leadership skills.
\end{abstract}

Key words: Head nurse, managerial skills and patient advocacy.

\section{Introduction}

Management is the creation and control of technological and human environment of an organization in which human skills and capacities of individuals and groups find full scope for their effective use in order to accomplish the objectives for which an enterprise has been set up. It is involved in the relationship of the individual, group, the organization and the environment. Management has been defined as the act of doing things through and with people in formally organized group (Dash, 2015).

Head nurse is the person who leads and manages nursing care for patients, families and communities in a variety of settings. She also is responsible for direction of human and material resources to achieve a desired goal. More ever, head nurse is the person who has the authority and responsibility to direct the employees. She guides and assists the employees to get the work done by them (Dash, 2015).

A head nurse who is well qualified in managerial skills will be able to provide standards and policies related to patient care to direct the staff nurses, orient and update them of the standard of patient care, implement the health care programs and standards of patient care, assume the role of patient advocate, cooperate with the health team members to coordinate medical and nursing management of patient care, considered as a resource member to health care team in assessing, planning, implementing and evaluating nursing care provided (Scribed, 2012).

Managerial skills provide knowledge and ability of the individuals in a managerial position to fulfill some 


\section{Head Nurses' Perception of Their Managerial Skills and Its Relation To Their Patient Advocacy}

specific managerial activities or tasks. This knowledge and ability can be learned and practiced. However, these also can be acquired through practical implementation of required activities and tasks. Therefore, each skill can be developed through learning and practical experience of the individuals (Sutevski, 2009). When we talk about head nurse's managerial skills, we talk about skills of head nurse to maintain high efficiency in the way how her employees complete their everyday working tasks (Builder, 2017).

Leadership skills are the skills needed to be able to influence an individual or group to attain the group's goal, at the same time maintaining the morale of the group (Krishna, 2014). The head nurse as a leader stimulates her staff to see possibilities for improvement in patient care, helps them decide what they want to do and gives encouragement every step of the way, by and large, leaders are democratic, they set an example in their attitudes towards patients, families, personnel and they plan a head. Additionally, leadership refers to the quality of the behavior of individuals nearby they guide people on their activities in an organization (Chavez and Yoder, 2014).

In nursing, technical skills are divided into nursing management technology and nursing practice technology. A technical skills are the ability to perform the given job. It helps the manager to use different equipment and tools. It also helps them to use various procedures and techniques. The head nurses require more technical skills because of being in charge of the actual operations (Akrani, 2011).

Conceptual skills are the abilities which allow a person to visualize concepts, see patterns, understand abstract ideas, solve problems, formulate processes and understand how systems, programs and ideas interrelate (Katz, 2011). These skills are often viewed as an essential requirement for head nurse. Moreover, Conceptual skills are the ability to visualize the organization as a whole. It includes analytical, creative and initiative skills. It helps the head nurse to solve the problems for the benefit of the entire organization. It helps the manager to fix goals for the whole organization and to plan for every situation (Michael et al., 2017).

Interpersonal skills mean the ability to work with other people. They include the ability to support and encourage others, being able to give and receive constructive critism as well as being able to negotiate (Boyd and Dare, 2014). Moreover, interpersonal skills are all activities, verbal and nonverbal, that people use when interacting directly with others. There are some attributes that are essential for effective interpersonal interaction: Self-awareness, effective listening, questioning, helping or facilitating, reflecting, assertiveness and nonverbal cues (Reading and Webster, 2014).

Advocacy as a philosophical principle in nursing was reported as being embedded in nursing practice and involved interceding on behalf of patients in ethical dilemmas (Zebrack, 2011). Moreover, Patient advocacy is a basic section of nurses' attempts to encourage and protect health and interests of patients by supplying information and assisting patients, selfdetermination, autonomy, or empowerment, pleading the reason of patient, protecting the patient from worries, revealing information about misbehavior that imperils the welfare of others, and respecting patients values and beliefs, together with 


\section{Head Nurses' Perception of Their Managerial Skills and Its Relation To Their Patient Advocacy}

educating and interceding (Fawzy, 2016).

Patient advocates defend the rights of patients, especially in settings such as hospitals, or outpatients after they have received care there. Patients often face complex webs of issues related to their health care that require learning un familiar information and making decisions that weigh heavily on them and that affect their lives for a long time after being healed or released from the hospital (Addario, 2017). The head nurse as a patient advocate must be equipped with a variety of skills to provide resources and comfort to patients these skills include: Helpfullness, communication, problem solving, patience, organization and relationship building (Andrea, 2017).

It is important for the patient advocate to have strong leadership skills. Expectations have been elevated and organizations look to patient advocates to translate the voice of the patient into actions that will improve quality and patient satisfaction. Patient advocates need to understand the organization's strategic goals especially goals around improving patient satisfaction, patient experience and service excellence (Windermere, 2017). The patient advocate can contribute information and patient feedback that will help develop process improvement in the organization. The patient advocates helps ensure the organization as a whole hears, understands, acknowledges and as possible acts on the voice of the patient during discussions about process $\backslash$ policy changes, construction design, physician and patient engagement...etc (Pedersen, 2015).

Patient rights are integral to patient advocacy. They can be classified into their rights related to treatment and their rights in the way of receiving treatment. These include; that every patient has the right to respect; dignity, integrity, safety, privacy, protection and cultural, religious and moral values with appropriate measures for disease prevention and health care. In addition, every patient has the right to receive information about health services and how best to use them, the right to receive information about health status on request; the right to refuse treatment, the right to complain, and the right to get informed consent, patients' autonomy, privacy and confidentiality (American cancer society, 2013).

(Chalkright, 2017) stated that head nurses need to have interpersonal skills, analytical problem solving, leadership coaching, influencing, data analysis and communication in order to accomplish their work effectively as a patient advocate. It is important also to have knowledge about patient rights and regulatory standards as well as understanding of the complaint and grievance process and great problem solving. In addition head nurses' experience preferred to be at least two years in health field to be effective patient advocate.

\section{Purpose of the study:}

The purpose of the present study was to assess head nurses' perception towards their managerial skills and its relation to their patient's advocacy at Benha University Hospital.

\section{Research questions:}

1) What is the head nurses' perception of their managerial skills?

2) What is the head nurses' perception of their responsibility regarding patient rights?

3) Is there a relationship between head nurses' perception of managerial skills and their perception of their responsibility regarding patient's rights? 


\section{Head Nurses' Perception of Their Managerial Skills and Its Relation To Their Patient Advocacy}

Methods:

\section{Research design:}

A descriptive correlational research design was used to carry out the study.

\section{Setting:}

The study was conducted at Medical and Surgical departments in Benha University Hospital.

\section{Sampling:}

It includes all head nurses and their assistants (68) who are responsible for administrative activities. This sample was available during the study time. They included head nurses and their assistants' in each unit of the above mentioned settings.

\section{Instruments for data collection:}

To collect data for this study, the following two instruments were used:

\section{Instrument one: Managerial Skills Questionnaire:}

It was developed by $\boldsymbol{A b d} \boldsymbol{R a b o , ~ ( 1 9 9 7 ) ~ a n d ~}$ used to assess head nurses' perception of managerial skills. It consisted of two parts.

First part: Personal data: This part included data about age, years of experience....etc).

Second part: It is composed of questions about managerial skills. There are 4 major groups which are subdivided as Leadership skills (25 items), Technical skills (9 items), Conceptual skills (9 items) and Interpersonal skills (23 items).

\section{Instrument two: Patient Advocacy Questionnaire:}

It was developed by the researcher after a thorough review of literature (American cancer society, 2013, Fawzy, 2014 and Galuska, 2016) to assess head nurses' perception of their responsibility for patients' rights' advocacy: It consisted of two dimensions: First dimension; head nurses' perception to patient rights (33 items) and Second dimension: Head nurses' perception of their responsibilities as a patient right' advocates, it contained (15 items).

\section{Statistical reliability of tools:}

Reliability of managerial skills questionnaire was measured by using Cronbach's Alpha and the value was (0.86) and reliability of patient advocacy questionnaire was measured by using Cronbach's Alpha and the value was (0.70).

\section{B-Pilot study}

The revised questionnaires were piloted with $10 \%$ from the subject 7 head nurses, their assistants, were included in the main study subject. It was done to evaluate the effectiveness of the proposed data collection tools, and to assess the feasibility of the study and estimate the time needed to fill them (15-20 minutes).

\section{Ethical consideration:}

A written consent for approval to participate was obtained from the head nurses and their assistants. They were informed about the purpose and benefits of the study and that their participation was voluntary and they had the right to refuse to participate in the study without giving any reason. In addition, confidentiality and anonymity of the subjects were assured through coding of all data.

\section{Procedure:}

1) An official letter was submitted from the Dean of the Faculty of Nursing in Benha to the director of the hospital explain the purpose and methods of data collection.

2) The actual field work took about three months; from June 2017 to August 2017 to collect data from field work. The data collected by the researcher from head nurses and their assistants through distribution of the questionnaire to them. The data collected during their work hours through 2 days/ week during the morning shift after explaining the aim of the study to head nurses as well as organize and arrange the head nurses' 


\section{Head Nurses' Perception of Their Managerial Skills and Its Relation To Their Patient Advocacy}

participation according to unit's needs and activities.

\section{IV- Statistical Analysis:-}

Data were verified prior to computerized entry. The statistical package for social sciences (SPSS version 11.0) was used for that purpose, followed by data analysis and tabulation. Descriptive statistics were applied (e.g., frequency, percentages, chisquare and correlation coefficient). Test of significance was done. A significant level value was considered when $\mathrm{p}<0.05$. And a highly significant level value was considered when $\mathrm{p}<0.01$.

\section{Results}

Table (1): shows that the total studied sample was 68 head nurses and their assistants. $60.3 \%$ of them working at general medical departments and the other $39.7 \%$ at general surgical departments .Regarding to their age nearly half (48.5\%) were aged from 30 to $<40$ years, with a mean age of $33.7 \pm 7.3$. Regarding to their education, most of them (85.3\%) had baccalaureate degree in nursing. As regards years of experience, the highest percent of them less than 10 years, with mean years of experience $12.32 \pm 8.7$.

Figure(1): illustrated that 50\%, 69.1\% as respectively of head nurses and their assistants had moderate perception to leadership and technical skills while 51.5, 55.9 as respectively of head nurses and their assistants had high perception to conceptual and interpersonal skills.

Figure(2): Illustrated that more than three quarters of head nurses and their assistants had perceived patient rights while more than two thirds of them prceived their responsibilities on patient advocacy.

Table (2): shows that there was a highly statistical significant correlation between head nurses and their assistants' perception to their total managerial skills and total patient advocacy

Table (1): Distribution of head nurses and their assistants regarding their personal characteristics $(N=68)$.

\begin{tabular}{|c|c|c|}
\hline \multirow[t]{2}{*}{ Personal characteristics } & \multicolumn{2}{|c|}{$($ Total $\mathrm{N}=68)$} \\
\hline & No & $\%$ \\
\hline 1. Department $\quad$ Medical & 41 & 60.3 \\
\hline Surgical & 27 & 39.7 \\
\hline 2. Age (years) & 23 & 33.8 \\
\hline $30-$ & 33 & 48.5 \\
\hline $40+$ & 12 & 17.6 \\
\hline Mean \pm SD & \multicolumn{2}{|c|}{$33.7 \pm 7.3$} \\
\hline $\begin{array}{l}\text { 3. Qualification } \\
\text { Master degree in nursing }\end{array}$ & 4 & 5.9 \\
\hline Baccalaureate degree in nursing & 58 & 85.3 \\
\hline Diploma in nursing & 6 & 8.8 \\
\hline 4. Experience (years) $<10$ & 34 & 50.0 \\
\hline $10-$ & 19 & 27.9 \\
\hline $15+$ & 15 & 22.1 \\
\hline Mean \pm SD & & \\
\hline
\end{tabular}


Head Nurses' Perception of Their Managerial Skills and Its Relation To Their Patient Advocacy

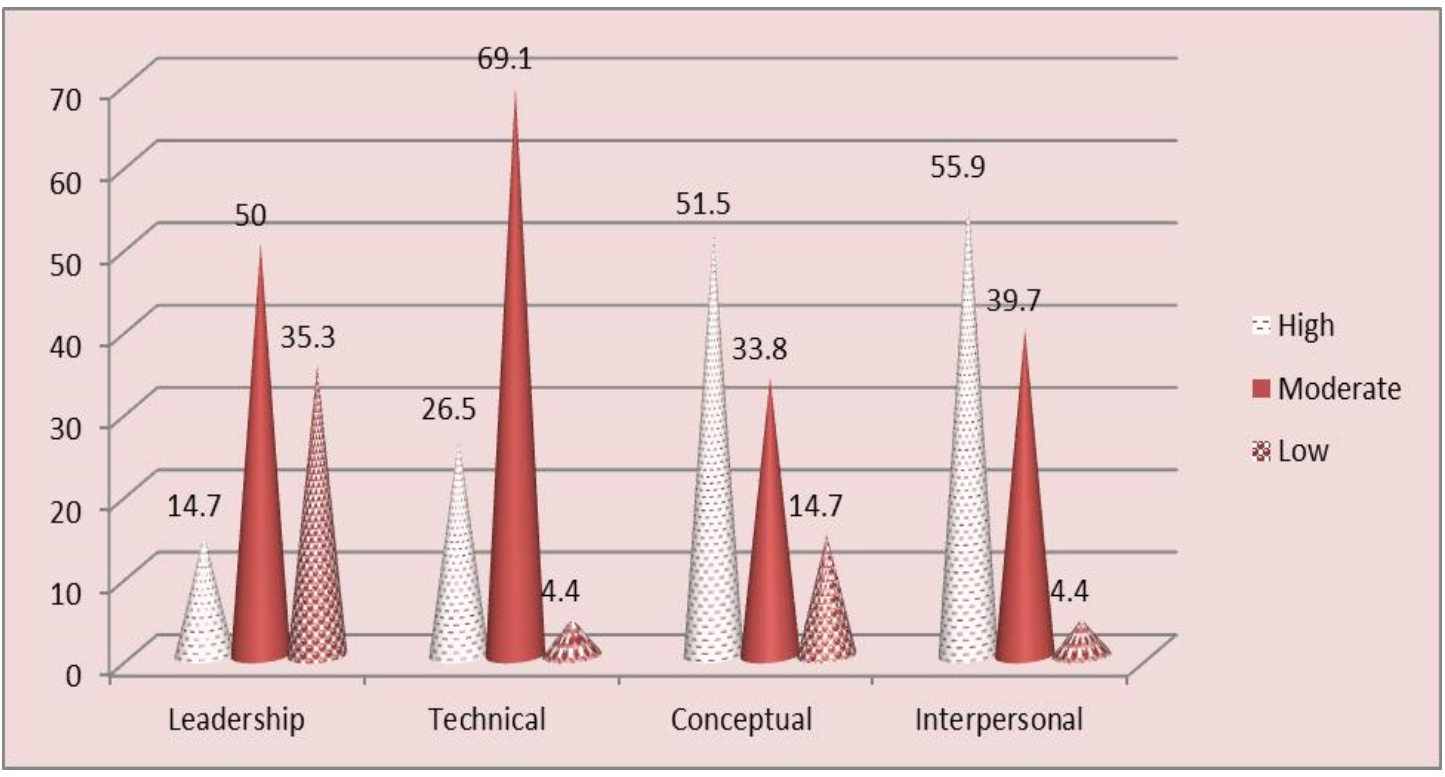

Figure (1): Distribution of head nurses and their assistants regarding their perception of total managerial skills $(n=68)$.

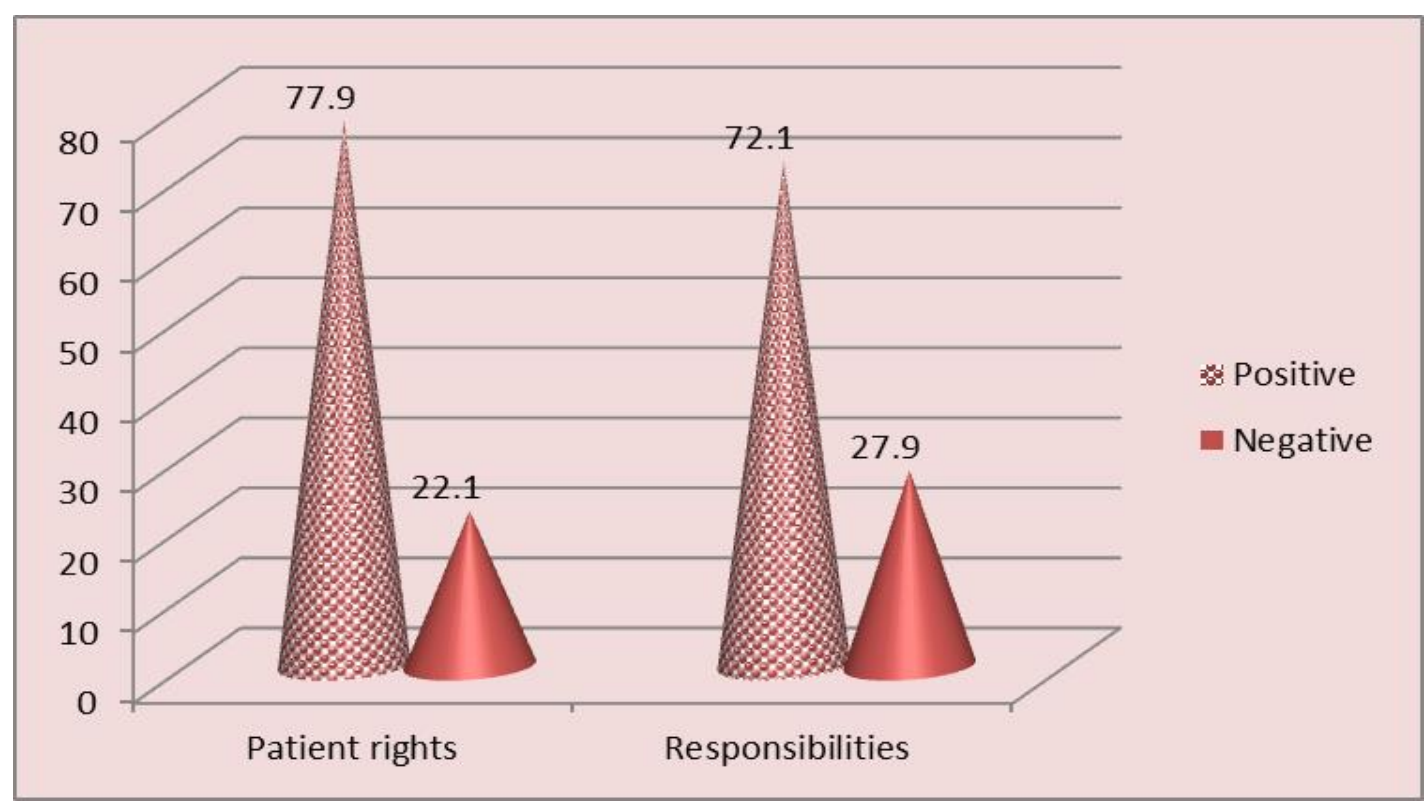

Figure (2): Frequency distribution of head nurses and their assistants regarding their perception of total patient advocacy $(n=68)$.

Table (2): Correlation between head nurses and their assistants' total managerial skills and total patient advocacy.

\begin{tabular}{|c|c|c|}
\hline \multirow{2}{*}{ Variables } & \multicolumn{2}{|c|}{ Total managerial skills } \\
\cline { 2 - 3 } & $\mathbf{r}$ & $\mathbf{p}$ - value \\
\hline Total patient advocacy & 0.64 & $\mathbf{0 . 0 0 2}$ \\
\hline
\end{tabular}

$\left({ }^{* *}\right)$ A highly statistical significance difference $\mathrm{P} \leq 0.001$.

\section{Discussion}


The study aimed to assess head nurses' perception toward their managerial skills and its relation to their patient advocacy at Benha University Hospital. That can be achieved through assessing head nurses' perception to their managerial skills, assessing head nurses' perception to their responsibilities on patient advocacy and investigating the relationship between head nurses' perception to their managerial skills and their perception to their patient advocacy at Benha University Hospitals.

Concerning perception of head nurses and their assistants to their total leadership skills, the results of the present study indicated that half of head nurses and their assistants had moderate perception to leadership skills. This is may be due to lack of training on leadership skills. This is consistent with Kantanen, et al., (2017) who evaluated head nurses' leadership skills to be quite good. On the other hand Divshali and Vanaki, (2016) found that acquiring crucial skills such as leadership skills is essential for the head nurse to fill full their job.

Concerning to perception of head nurses and their assistants to their total technical skills, the finding of the current study revealed that more than two thirds of the studied head nurses and their assistants had moderate perception to total technical skills. This may be due to that the head nurse as a leader doesn't necessarily need to understand all technical details rather than the ability to use the available resources. The result of the current study is agree with Keil, (2013) who demonstrated that it isn't critical for the nurse managers to have technical skills, the manager needs to have good technical people on the staff, but he as a leader doesn't need to understand all these details.
In relation to perception of head nurses and their assistants toward total conceptual skills, the finding of the current study indicated that more than half of head nurses and their assistants had high perception to this skill. This may be due to high educational level and experience. This result is consistent with Mamdouh, (2011) who stated that nursing managers were performing adequate planning. It was also supported by Keil, (2013) who indicated that managers need good planning skills to successfully achieve the goals of organization.

Concerning to interpersonal skills, the result of the current study revealed that more than half of the studied head nurses and their assistants had high perception to total interpersonal skills. This could be due to the importance of human relations on nursing profession. This result agreed with Vegsund, (2014) who conducted study about "work engagement among nurses" found that head nurse can foster communication and provide staff nurses with opportunity to express feelings and thoughts for sharing good experiences to reduce conflicts and solve problems in a constructive way.

As regards perception of head nurses and their assistants toward total patient rights, the majority of head nurses and their assistants had positive perception of patient rights. This could be due to high educational level and experience of head nurses.

Regarding to head nurses and their assistants' total responsibilities on patient advocacy, the conducted study declared that more than two thirds of head nurses and their assistants had positive perception of their responsibilities on patient advocacy. This may be due to the majority of participants of the current study high qualified nurse with baccalaureate 
degree in nursing and aware of principles of advocacy and also have authority as a nurse manager. The finding of the conducted study agreed with the study conducted by Kibble, (2012) in United States of America title of the study was "nursing attitude and perception toward patient advocacy" he stated that lake of authority of nursing is hindering their role as a patient advocate.

This result is in contrast with Fawzy, (2016) who stated that the totals proactive nursing advocacy was moderate.

As regards the correlation between head nurses' total managerial skills and patient advocacy, the current findings declared that there was a highly significant correlation between head nurses and their assistants' perception to their managerial skills and their perception to their patient advocacy. This means when head nurses' perception to their managerial skills increase, their perception to patient advocacy increase. This probably due to that patient advocates need specific skills for effective patient advocacy.

This finding is supported by Mary, (2017) who stated that every leader must cultivate ethical leadership qualities to build his own moral compass to guide staff nurse competent and ethical nursing care and provide a model for other nurses to follow which reflected on the patient. He also stated that interpersonal communication is a necessary component of ethically leading other nurses and advocating for patients.

Moreover, the current findings in line with Butts, (2013) who showed that leaders can promote patient advocacy in nursing through creating or revising protocols, policies or procedures to reflect evidence based practice in a way that encourages positive patient outcomes and promotes patient safety by reducing errors and confirming negligence in practice. Moreover, ethical leaders in nursing can lead changes in organizations that support the culture of patient advocacy.

This positive correlation could be attributed to the fact that skillful and effective clinical leaders have been characterized by having advocacy skills and the ability to change and encourage better climate of patient safety (Daly, 2014).

\section{Conclusions}

It is concluded that $50 \%, 69.1 \%$ as respectively of head nurses and their assistants had moderate perception to total leadership and technical skills while $51.1 \%, 55.9 \%$ as respectively had high perception to total conceptual and interpersonal skills. More than three quarters $(77.9 \%)$ of head nurses and their assistants perceived the patient rights while $72.1 \%$ of them perceived their responsibilities on patient advocacy. There was a highly significant correlation between head nurses and their assistants' perception to their managerial skills and their patient advocacy.

\section{Recommendations}

1) Head nurses and their assistants should be trained on leadership skills especially describing and evaluating plans for achieving units' goals.

2) Head nurses and their assistants need training on technical skills especially distributing the daily responsibilities according on patients' needs and nursing team qualification.

3) Hospital management has to develop clear policies regarding patient rights.

4) Head nurses and their assistants should pay attention to the patient right to be consulted before being 
photographed for any scientific purpose, know the name of health care team and their specialist and refuse the treatment regimen.

5) Collaboration should be planned between hospitals and faculty of nursing to provide regular education to all health care team about patient rights and advocacy.

6) Further researches are recommended to be done in the future to:

- Identify effect of managerial skills program on head nurses and their assistants' perception to technical and leadership skills.

- Assess patient point of view regarding their achievement of rights.

\section{References}

Abdullah, A. (2015): Nursing satisfaction in a Magnet Hospital, Unpublished PHD Theses, University of Rhode Island.

Addario, B. (2017): The role of patient advocacy groups: Journal of Thoracic Oncology, 1(12): 147-148.

Akrani, G. (2011): Levels of management. Available At: Kalyan-city.

Blogspot.com.eg.levels-ofmanagement, Retrieved in 5-12011.

American Association of Collges of Nursing. (2013): Fact sheet. Creating a more highly qualified nursing work force. Available

At: http://www.aacn.nche.edu, Retrieved in 13-5-2013.

Boyd, C \& Dare, J. (2014): Comunication skills for nurses. $\left(1^{\text {st }} \mathrm{Ed}\right)$. John wiley Co: In London, P.49.

Builder, C. (2017): What are management skills and why are they important? Available At: https://www.careerbuilder.com/ advice/what-are-managementskills-and-why-they-areimportant, Retrieved in 14-32017.

Chalkright, D. (2017): Advocating with confidence, does past experience help? Journal of Neonatal Nursing, 2 (23): 8285.

Chavez, EC \& Toder, LH. (2014): Staff nurse clinical leadership. Available At: https://www.ncbi.nlm.nih.gov/p ubmed, Retrieved in 17-1-2014.

Dash, M. (2015): Ward management and administration for nurses, $\left(1^{\text {st }}\right.$ Ed). Jaypee brothe Fatchett \& Anita. (2012): Social policy for nurses. Available At: https: //en.wikipedia.org/wiki/nursingmanagement, Retrieved in 17-42012.

Divshali, M \& Vanaki, Z. (2016): Effect of head nurse empowerment program on staff nurses' job satisfaction at two educational hospitals in Rasht, Iran. Iranian Journal of Nursing and Midwifery Research; 21(3): 306-309.

Fawzy, A. (2016): Relationship between nursing staff perception and attitude toward scientific nursing research and patient advocacy. Master thesis. Faculty of nursing. Cairo university, Egypt.P.3.

Kantanen, K, Kaunonen, M\& Helminen, M. (2017): leadership and management competencies of head nurses and directors of nursing in finnish social and health care. Nursing Research Journal; 3(22): 58-61. 
Keil, M. (2013): Understanding the most critical skills for managing IT projects. Available At: http.www.sciencedirect.com, Retrieved in 16-11-2013.

Krishna, M. (2014): What is conceptual skill? Whether conceptual skill help develop and promote team spirit? Available At: https: //www.bayt.com/en/specialist, Retrieved in 14-11-2014.

Mamdouh, S (2011): Management functions performed various nursing managerial levels and their perception. Master Thesis. Faculty of Nursing. Menoufia University, Egypt.

Michael, D. Mumford, Erinmichelle todd, Cory Higgs, Tristan Mcintosh. (2017): Cognitive skills and leadership performance: The nine critical skills, 1(28): 24-39.

Pederson, K. (2015): Patient advocate: A critical role in patient experience.Available At: http://jgh.ca/uploads/pacwp.pdf, Retrieved in 4-4-2015.

Reading, S \& Webster, B. (2014): Achieving competencies for nursing practice. $\left(2^{\text {nd }} \mathrm{Ed}\right)$. In London. P.59.

Robert, K. (2011): Management. Available At: http:Kalyan-cityblog spotcom.eg/m managerial-skills-conceptualhuman. Html, Retrieved in 106-2011.

Scribed, (2012): head nursing tool. Available At: www.scribed.com/doc, Retrieved in 5-9- Windermere, A. (2017): What skills do patient advocates require, Available At: work.chron.com/skills-patientadvocates-require, Retrieved in 15-1-2-17.

Sutevski, D. (2009): What are managerial skills. Available At: http:

Ilwww.entrepreneurshipinabox. com, Retrieved in 27-7-2009.

Zebrack, B. (2011): An advocate's persepective on cancer supervisorship. Seminars in oncology nursing, 4(17): 284287.

Vegsund, P. (2014): Work engagement among nurses, Master Thesis in Health Science and Technology, Norwegian University of Science and Technology, pp. 5, 39-40.

Kibble, G. (2012): Patient advocacy in nursing practice. (Published master thesis), Turku University of Special Sciences. pp. 7-20.

Fawzy, A. (2016): Relationship between nursing staff perception and attitude toward scientific nursing research and patient advocacy. Master thesis. Faculty of nursing. Cairo university, Egypt.P.3.

Mary, S. (2017): The ethics/ advocacy connection. Nursing Management; 48 (8): 18-23.

Butts, J. (2013): Ethics in professional nursing practice. Nursing Ethics across the Curriculum and into Practice, 38(11): 69-98.

Daly, J. (2014): The importance of clinical leadership in the hospital setting. Available At: https: //www.doveprss.com, Retrieved in 21-11-2014 